\title{
Mathematical Modeling of Oscillating Water Columns Wave-Structure Interaction in Ocean Energy Plants
}

\author{
Aitor J. Garrido, ${ }^{1}$ Erlantz Otaola, ${ }^{1}$ Izaskun Garrido, ${ }^{1}$ Jon Lekube, ${ }^{1}$ \\ Francisco J. Maseda, ${ }^{1}$ Pedro Liria, ${ }^{2}$ and Julien Mader $^{2}$ \\ ${ }^{1}$ Automatic Control Group (ACG), Institute of Research and Development of Processes, Department of Automatic Control and \\ Systems Engineering, University of the Basque Country (UPV/EHU), P Rafael Moreno 3, 48013 Bilbao, Spain \\ ${ }^{2}$ Marine Research, AZTI-Tecnalia, Herrera Kaia, Portualdea, 20110 Pasaia, Spain
}

Correspondence should be addressed to Aitor J. Garrido; aitor.garrido@ehu.es

Received 17 April 2015; Revised 23 June 2015; Accepted 24 June 2015

Academic Editor: Yong Liu

Copyright (c) 2015 Aitor J. Garrido et al. This is an open access article distributed under the Creative Commons Attribution License, which permits unrestricted use, distribution, and reproduction in any medium, provided the original work is properly cited.

\begin{abstract}
Oscillating Water Column (OWC)-based power take-off systems are one of the potential solutions to the current energy problems arising from the use of nuclear fission and the consumption of fossil fuels. This kind of energy converter turns wave energy into electric power by means of three different stages: firstly wave energy is transformed into pneumatic energy in the OWC chamber, and then a turbine turns it into mechanical energy and finally the turbogenerator module attached to the turbine creates electric power from the rotational mechanical energy. To date, capture chambers have been the least studied part. In this context, this paper presents an analytical model describing the dynamic behavior of the capture chamber, encompassing the wave motion and its interaction with the OWC structure and turbogenerator module. The model is tested for the case of the Mutriku wave power plant by means of experimental results. For this purpose, representative case studies are selected from wave and pressure drop input-output data. The results show an excellent matching rate between the values predicted by the model and the experimental measured data with a small bounded error in all cases, so that the validity of the proposed model is proven.
\end{abstract}

\section{Introduction}

At present, the safety of the energy obtained by means of nuclear fission is being questioned due to waste disposal issues and accidents such as the one at Fukushima. Besides, continued consumption of fossil fuels threatens the health of the planet and contributes to global warming. To avoid these consequences, a transition to clean energy sources is urgently needed $[1-3]$. Here is where the need for renewable energies arises [4-6].

Among these kinds of energy, ocean energy is expected to play a principal role in future years. According to some works, $100 \%$ of total energy consumption could be obtained from solar, wind, and wave energy [7-9]. Likewise, according to European Union (EU) reports, worldwide energy requirements could be fulfilled with just $0.1 \%$ of the total ocean energy available [10]. In this respect, the most promising devices for harnessing the power of the sea are based on wave and tidal power [11], with a high potential power density [4].
Currently, there is a wide variety of point absorbers and on-shore devices based on different technologies to harness wave energy (OWC systems, hinged contour devices such as the Pelamis, overtopping devices such as the Wave Dragon, etc. $[12,13])$. Of these, OWC-based devices are the most popular due to their characteristics and stage of development [14$16]$.

The Nereida MOWC is a project based on this technology located in the town of Mutriku, Gipuzkoa, Basque Country (Figure 1). Within this project, the Basque Energy Board (EVE) has installed an OWC-based power plant along the shoreline of this town, composed of $1618.5 \mathrm{~kW}$ turbines [17].

In this context, this work is focused on the development of an analytical model of the OWC capture chamber in this kind of system and its interaction with the ocean waves (Figure 2). The proposed model is also tested and validated by means of experimental results for the particular case of Mutriku OWC wave power plant. 


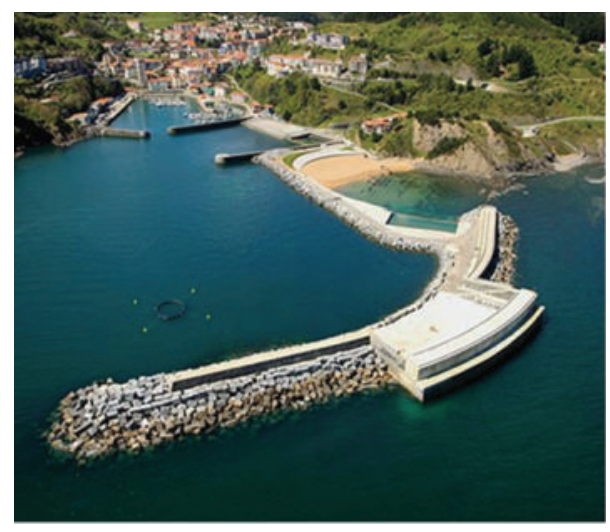

FIGURE 1: OWC power plant at Mutriku.

The rest of the paper is organized as follows. Section 2 provides some background on OWC systems, the Wells turbine, and wave theories. In Section 3, development of the model is presented. In Section 4, experimental data sets are analyzed and the model is implemented and tested. Finally, concluding remarks end the paper in Section 5.

\section{Background}

An Oscillating Water Column (OWC)-based energy converter (Figure 3) is basically a device that transforms the mechanical energy of the waves into electric power.

The main part of the converter is the capture chamber, which is composed of a fixed structure whose lower part is open to the sea water below the still water level (SWL) [18]. The waves entering the chamber compress and decompress the air around this SWL so that an oscillating airflow is created. This airflow is passed through a power take-off (PTO) system consisting of a turbine and an induction generator that transforms this motion into electrical power [19] (see Figure 4).

Currently, two different types of turbine are mainly used in power plants around Europe, India, Japan, Korea, and so forth [20]: the Wells turbine [21-24] and impulse turbine [25].

In particular, the type used in Mutriku is a Wells turbine (see Figure 5). The geometry of this kind of turbine allows a unidirectional rotational movement to be maintained regardless of the airflow direction [20, 23-25]. However, the symmetric profile that allows this self-rectifying property also produces an undesired behavior: the stalling effect. This phenomenon causes the turbine to stall when the airflow exceeds a certain value, greatly decreasing its efficiency [25].

In order to minimize this efficiency issue and, therefore, to maximize the power extraction, diverse kinds of control schemes can be used [26-45], such as controlling the rotational speed or adjusting the airflow through the blades by means of a control valve $[5,46]$.

As has been shown, the performance of the OWC converter depends on the different energy exchanges that take place during the process and in particular on the conversion of wave energy into pneumatic energy inside the capture chamber, so it is necessary to understand the dynamics of the waves and the corresponding theories.

Amongst these theories [47], Stokes second- and higherorder theories, cnoidal wave theory, and particularly Airy linear theory [48] should be highlighted.

The latter is widely employed to model the kinematics of the waves' surface. According to it, wind waves can be described as ideal sinusoidal waves, neglecting second-order effects such as friction losses, turbulence, and other energy losses [5].

In the particular case of Mutriku, with a depth $h$ over 5 meters from the SWL, an average main period of 12 seconds, and a mean amplitude around 1 meter, waves are taken as intermediate waves, so Airy linear theory can be applied. Also, monochromatic unidirectional waves are considered [49-51].

\section{Model Statement}

In this section, the interaction of the waves with the OWC chamber structure is modelled [51]. In order to analyze the airflow dynamic performance in the capture chamber, it is first necessary to describe the wave's propagation behavior. Hence, the task of modeling the behavior of the capture chamber is divided into three phases. Firstly, a model describing the wave surface dynamics is provided. Then, this model is related with the pressure change in the OWC chamber and, in particular, with the pressure drop in the turbine's blades, detailing the relation between the waves and the airflow through them. Finally, the mechanical characteristics are taken into account to obtain the resulting rotational speed and torque to be applied to the induction generator.

3.1. Wave's Surface Dynamics. According to the Airy linear theory [48],

$$
y(t)=a \cdot \sin (\omega \cdot t)=a \cdot \sin (2 \pi f \cdot t),
$$

where $c=\lambda f$, so that

$$
y(t)=a \cdot \sin \left(\frac{2 \pi}{\lambda} \cdot c t\right) .
$$

This expression represents the temporal variation for a wind wave of amplitude $a$, wavelength $\lambda$, and propagation speed $c$, as a macroscopic representation of the oscillating behavior of water particles at a specific point. It is now necessary to consider a new variable corresponding to the spatial dimension in the wave's front direction in order to transfer the oscillation movement to any point of the surface [52]:

$$
y(x, t)=a \cdot \sin \left[\frac{2 \pi}{\lambda}(c t-x)\right] .
$$

Then, take into account that the wave number, $k$, is defined as

$$
k=\frac{2 \pi}{\lambda}
$$

so that (3) may be written as

$$
y(x, t)=\frac{H}{2} \cdot \sin (\omega t-k x)
$$

where $H$ denotes the wave height. 


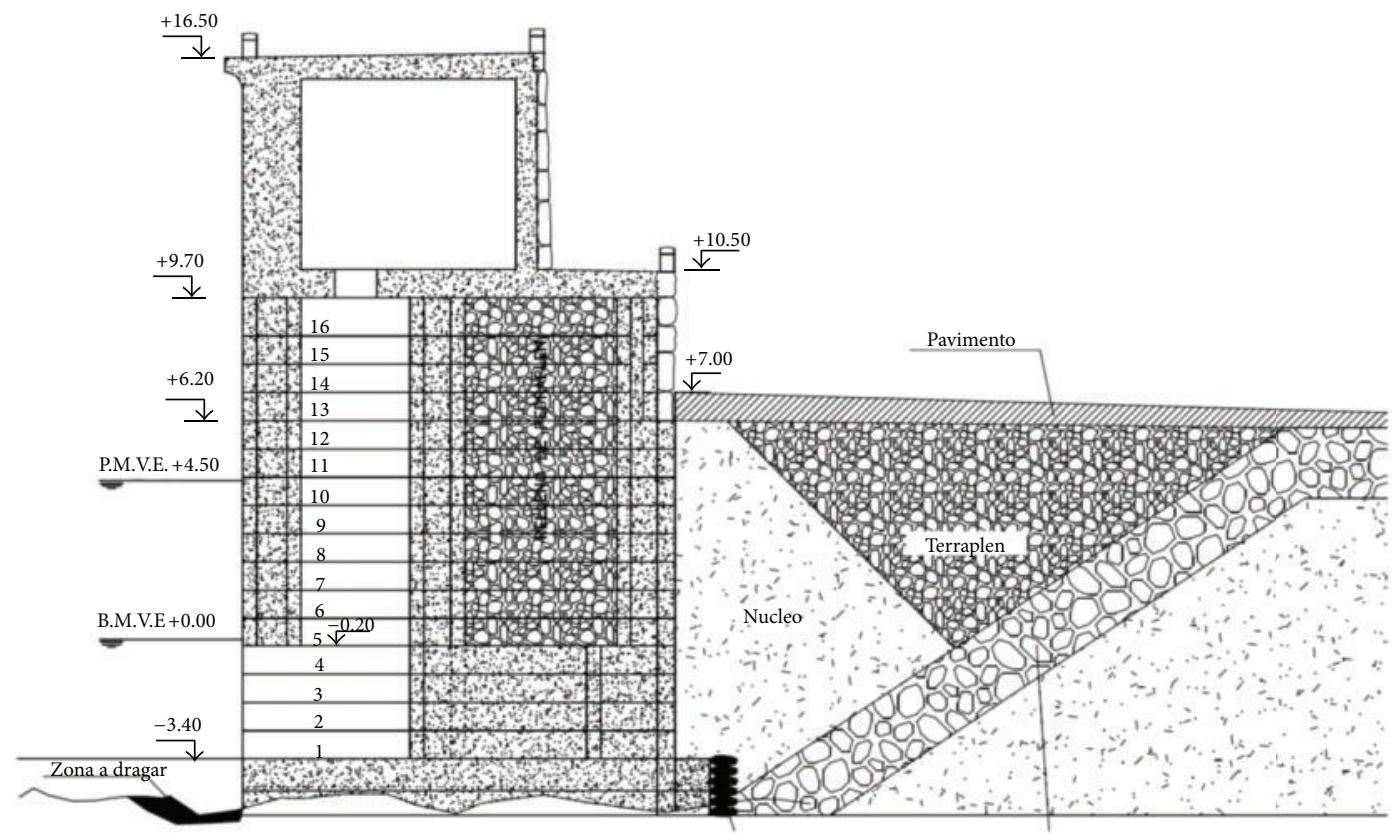

FIGURE 2: Capture chamber construction plan of Mutriku wave plant.

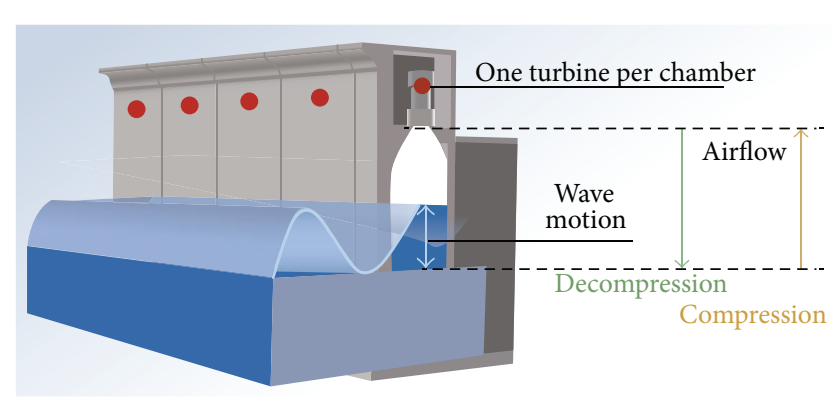

FIGURE 3: On-shore MOWC system schematic.

This expression represents the surface dynamics of a monochromatic linear wave as a function of the wave parameters [52].

3.2. Capture Chamber Model. The final aim is to obtain the torque and angular speed of the turbine that serve as inputs of the turbogenerator. These variables are indirectly related, as it will be shown, to the axial speed of the airflow through the turbine's blades [51].

The water volume may be used to calculate the air volume in the OWC chamber:

$$
V(t)=V_{c}-V_{w}(t)
$$

where $V_{c}$ and $V_{w}$ represent the capture chamber and water volumes, respectively.

Then, by integrating the orthogonal variation of the water surface along the area of the chamber:

$$
V(t)=V_{c}-\iint y(x, t) d A
$$

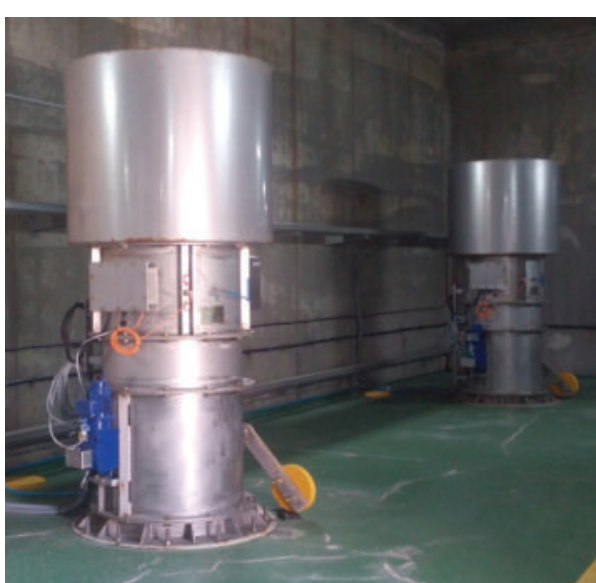

FIGURE 4: Turbogenerator modules.

Due to the geometry of the OWC chamber,

$$
d A=w \cdot d x
$$

where $w$ is the width of the chamber.

Therefore, one has

$$
V(t)=V_{c}+\frac{w H}{k} \sin \frac{k l}{2} \sin \omega t,
$$

where $l$ denotes the length of the chamber.

Now, it is possible to obtain the expression of the instantaneous airflow:

$$
Q_{a}(t)=w H c \cdot \sin \frac{k l}{2} \cos \omega t
$$




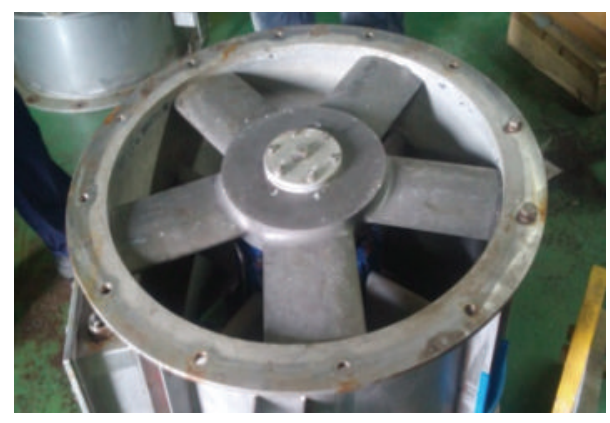

FIGURE 5: Wells turbine in Mutriku wave plant.

From this expression and taking into account the topology of the OWC chamber in Mutriku, where the airflow is conducted through a second axisymmetric duct where the turbogenerator module is located (see Figure 2), it is possible to obtain the expression of the axial airflow speed $(v=Q / A)$ :

$$
v_{t}(t)=\frac{8 a w c}{\pi D^{2}} \cdot \sin \frac{\pi l}{c T} \cos \frac{2 \pi}{T} t,
$$

where $D$ denotes the diameter of the duct.

3.3. Turbine Model. From the previous results and the turbine parameters, it is possible to obtain the pressure drop (dp) through [6]

$$
\mathrm{dp}=C_{a} \frac{\rho b l_{1} n}{2} \frac{1}{a_{1}}\left(v_{t}^{2}+\left(r \cdot \omega_{t}\right)^{2}\right),
$$

where $\rho$ is air density $\left(\mathrm{kg} / \mathrm{m}^{3}\right), b$ is blade's height $(\mathrm{m}), l_{1}$ is length of blade's chords $(\mathrm{m}), n$ is number of blades, $a_{1}$ is blade's section area $\left(\mathrm{m}^{2}\right), r$ is turbine's mean diameter $(\mathrm{m})$, and $\omega_{t}$ is turbine's angular speed ( $\mathrm{rad} / \mathrm{s})$.

This expression is obtained by applying Bernoulli's equation across the disc, taking into account that, under steady conditions, the total energy of the flow remains constant provided no work is done on the fluid [53]. As it is shown, the pressure drop also depends on the rotational speed, which is related with every torque applied to the turbine. This interaction may be modeled by means of Newton's Second Law applied to the rotational motion [5]:

$$
H \dot{\omega}_{t}+F \omega_{t}+T_{e}=T_{t},
$$

where $H$ is inertia coefficient, $F$ is friction coefficient, $\omega_{t}$ is rotational speed, $T_{t}$ is turbine torque, and $T_{e}$ is electrical torque (applied by the inductor generator).

Besides, the torque generated by the turbine follows the expression [5]:

$$
T_{t}=C_{t} K r\left[v_{t}^{2}+\left(r \omega_{t}\right)^{2}\right]
$$

As may be observed from the previous three equations, there exists a feedback between the behavior of the turbogenerator and the pressure drop through the turbine blades, since the pressure drop through the turbine depends on the rotational

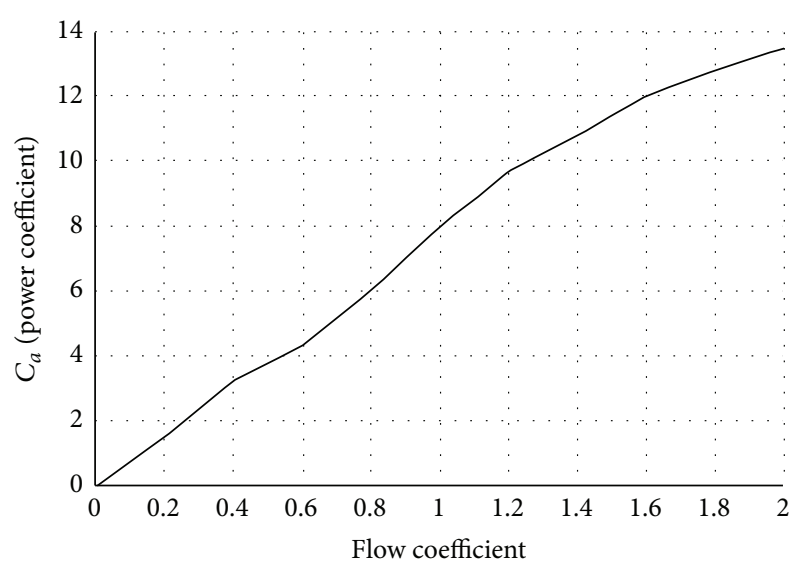

FIgURE 6: Power coefficient versus flow coefficient.

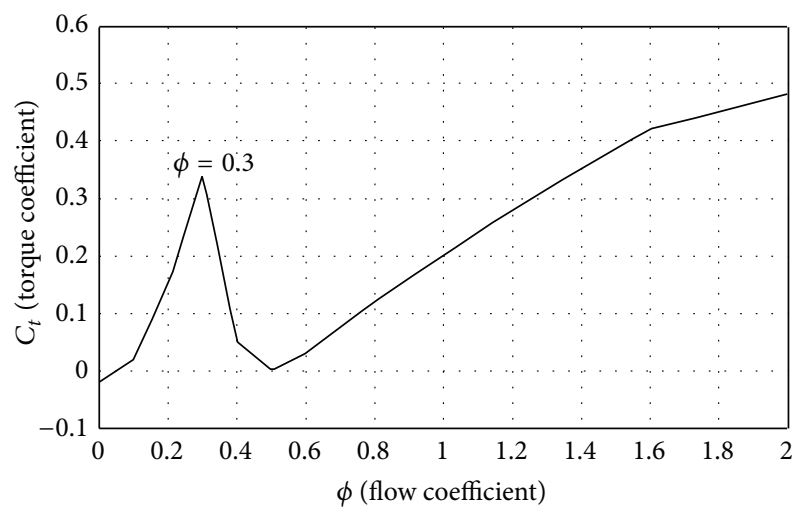

Figure 7: Torque coefficient versus flow coefficient.

speed but, also, the generated pressure drop influences the rotational speed by means of the applied torque (see Figure 15).

Also, in order to solve the aforementioned expressions, it is necessary to compute the power coefficient $\left(C_{a}\right)$ and the torque coefficient $\left(C_{t}\right)$, related to the flow coefficient $(\phi)$ by means of the characteristic curves of the turbine (Figures 6 and 7) [6].

In turn, the flow coefficient may be calculated as follows:

$$
\phi=\frac{v_{t}}{r \cdot \omega_{t}} .
$$

As a result, and recalling (12), it is possible to derive an expression for the pressure drop through the turbine in terms of the wave features, the ocean structure's characteristics, and the turbogenerator behavior as follows, $f(\cdot)$ being a function matching the $C_{a}$ and $\phi$ values according to the corresponding turbine characteristics:

$$
\begin{aligned}
\mathrm{dp} & =f\left(\frac{v_{t}}{r \cdot \omega_{t}}\right) \cdot \frac{\rho b l_{1} n}{2} \\
& \cdot \frac{1}{a_{1}}\left(\left(\frac{8 a w c}{\pi D^{2}} \cdot \sin \frac{\pi l}{c T}\right)^{2} \cos ^{2} \frac{2 \pi}{T} t+\left(r \cdot \omega_{t}\right)^{2}\right) .
\end{aligned}
$$


TABLE 1: Parameters of the Wells turbine and OWC chamber.

\begin{tabular}{lc}
\hline Air density $(\rho)$ & $1.19 \mathrm{~kg} / \mathrm{m}^{3}$ \\
Blade height $(b)$ & $0.03 \mathrm{~m}$ \\
Length of blade's chord $\left(l_{1}\right)$ & $0.165 \mathrm{~m}$ \\
Number of blades $(n)$ & 5 \\
Blade's section area $\left(a_{1}\right)$ & $0.004 \mathrm{~m}^{2}$ \\
Turbine's mean diameter $(r)$ & $0.375 \mathrm{~m}$ \\
Chamber width $(w)$ & $4.5 \mathrm{~m}$ \\
Chamber length $(l)$ & $4.3 \mathrm{~m}$ \\
\hline
\end{tabular}

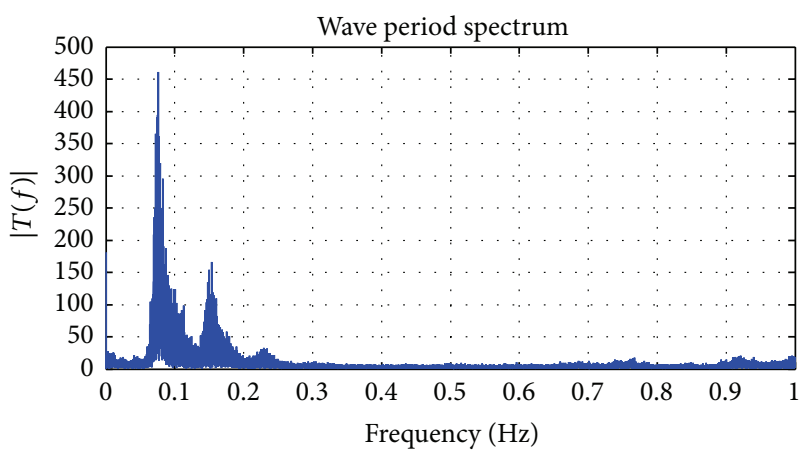

FIGURE 8: Frequency analysis of the waves.

\section{Model Implementation and Experimental Validation}

This section is devoted to the implementation of the wavestructure interaction model previously obtained and its validation by means of experimental data available from Mutriku wave plant. For data validation convenience, a model based on mean values data is also used.

The validation data sets correspond to wave data on different representative sea states collected by AZTI-Tecnalia at the Mutriku plant breakwater, and the corresponding Mutriku wave plant data are provided by the Basque Energy Board (EVE) for the same periods.

4.1. Mutriku Wave Plant: Experimental Validation Data. The aim of this subsection is to establish the parameters of the OWC chamber and the Wells turbine and to analyze the experimental data available from Mutriku wave plant.

On the one hand, the values of the parameters of the turbine and capture chamber expounded in the previous sections (see Figures 2 and 5) for the case of Mutriku wave plant are shown in Table 1.

On the other hand, from the experimental data obtained from Mutriku wave plant, a spectral analysis of the waves arriving at the plant can be obtained from representative pressure drop data sets (Figure 8).

Figure 8 shows that the main frequency of the waves is $0.08 \mathrm{~Hz}$, which corresponds to a 12.5 -second period, with a second harmonic around $0.165 \mathrm{~Hz}$ that provides a significant period $T=6$ seconds. This information is of great relevance in order to choose adequate data to test the model.
Taking into account these results, representative experimental data, from May 12, 2014, whose wave main characteristics may be summed up as shown in Table 2, has been considered.

For this date, detailed 20-minute input wave surface elevation data series were collected every 2 hours with a sampling period of 0.5 seconds. These data were derived from the high frequency measurements of the orbital velocities close to the surface, using an Acoustic Doppler Current Profiler (Workhorse $600 \mathrm{kHz}$ from Teledyne RDI). And analogous experimental data series are available for $\mathrm{dp}$ and $P$ from Mutriku wave plant for the same periods.

From these data, the mean wave period and the mean wave amplitude are particularly relevant, as depicted in Figure 9.

Also, the prevailing values of wave amplitude and periods for the chosen data sets are shown in Figure 10.

It may be observed that while the wave amplitude presents some predominant values (i.e., 0.5 and $0.25 \mathrm{~m}$ ), with a mean value of $0.43 \mathrm{~m}$ as shown in Table 2, the wave period values vary from 1.5 to 12 seconds with a mean value of 5.8 seconds, corresponding to the second harmonic of the spectral analysis of Figure 8 previously mentioned.

Once adequate experimental validation data sets have been chosen, the next step is to validate the proposed model by comparing the results of the model against real output data for the same wave input data. To do so, a mean values model that provides convenient general results has been used and afterwards analogous studies are performed for the full instantaneous model.

4.2. Mean Values Model. From (16), it is easy to obtain the expression that represents the mean pressure drop produced in the capture chamber for certain wave features, given the OWC structure characteristics:

$$
\begin{aligned}
& \mathrm{dp}_{\text {mean }} \\
& =f\left(\frac{v_{t}}{r \cdot \omega_{t}}\right) \\
& \quad \cdot \frac{\rho b l_{1} n}{2} \frac{1}{a_{1}}\left[\left(\frac{8 a w c}{\sqrt{2} \pi D^{2}} \cdot \sin \frac{\pi l}{c T}\right)^{2}+\left(r \cdot \omega_{t}\right)^{2}\right] .
\end{aligned}
$$

In order to simulate and validate the model, measured wave data for Mutriku plant breakwater are employed. Also, according to the Airy linear theory [52], the mean propagation speed can be calculated from $c=\sqrt{g h}$, where $h$ is the distance from the seafloor to the SWL.

For this purpose, three different representative data sets have been chosen as case studies.

4.2.1. First Case Study: May 12, 2014, $6.00 \mathrm{am}$. For this case study, a 20-minute dp data series with $2 \mathrm{~Hz}$ sampling rate was selected as shown in Figure 11. From this data, it is possible to extract the real measured experimental mean value of $3018 \mathrm{~Pa}$, whereas the corresponding theoretical mean value obtained from the proposed mean value model is $2921.3 \mathrm{~Pa}$. This represents a difference of 200.1 Pa between the measured 
TABLE 2: Wave main characteristics.

\begin{tabular}{|c|c|c|c|c|c|c|c|c|}
\hline Hour & HS & T3 & $\mathrm{HT}$ & $\mathrm{TT}$ & $\mathrm{NZ}$ & TB & $\mathrm{HB}$ & $\mathrm{HV}$ \\
\hline 0:00:00 & 1.768 & 9.424 & 2.313 & 9.609 & 188 & 6.38 & 1.032 & 1.206 \\
\hline 2:00:00 & 1.564 & 8.754 & 1.989 & 9.575 & 193 & 6.215 & 0.958 & 1.093 \\
\hline 4:00:00 & 1.513 & 9.064 & 1.821 & 9.138 & 181 & 6.627 & 0.941 & 1.063 \\
\hline $6: 00: 00$ & 1.724 & 9.624 & 2.168 & 9.627 & 167 & 7.183 & 1.052 & 1.202 \\
\hline 12:00:00 & 1.416 & 8.756 & 1.711 & 9.163 & 208 & 5.767 & 0.839 & 0.961 \\
\hline $14: 00: 00$ & 1.367 & 7.949 & 1.785 & 9.629 & 241 & 4.977 & 0.791 & 0.924 \\
\hline 16:00:00 & 1.319 & 7.92 & 1.725 & 8.529 & 241 & 4.977 & 0.757 & 0.891 \\
\hline 18:00:00 & 1.419 & 9.221 & 1.787 & 9.513 & 202 & 5.938 & 0.835 & 0.975 \\
\hline 20:00:00 & 1.144 & 8.933 & 1.484 & 9.59 & 211 & 5.685 & 0.663 & 0.778 \\
\hline 22:00:00 & 1.33 & 8.223 & 1.831 & 9.477 & 225 & 5.331 & 0.797 & 0.926 \\
\hline Hour & $\mathrm{HR}$ & HSS & T01 & T02 & $\mathrm{TP}$ & HMAX & PMAX & $\mathrm{TE}$ \\
\hline 0:00:00 & 1.33 & 1.882 & 7.353 & 5.842 & 9.635 & 3.009 & 11.708 & 10.864 \\
\hline 2:00:00 & 1.181 & 1.672 & 6.876 & 5.43 & 11.935 & 2.569 & 7.716 & 9.905 \\
\hline 4:00:00 & 1.135 & 1.607 & 6.943 & 5.545 & 11.935 & 2.338 & 10.012 & 10.359 \\
\hline $6: 00: 00$ & 1.225 & 1.734 & 7.243 & 5.605 & 11.055 & 2.922 & 11.237 & 10.41 \\
\hline 12:00:00 & 1.044 & 1.478 & 6.369 & 4.905 & 11.055 & 2.026 & 9.155 & 9.513 \\
\hline s14:00:00 & 1.055 & 1.493 & 5.885 & 4.414 & 11.055 & 2.34 & 9.998 & 9.262 \\
\hline $16: 00: 00$ & 1.01 & 1.43 & 5.872 & 4.457 & 9.635 & 2.389 & 9.409 & 8.916 \\
\hline 18:00:00 & 1.075 & 1.522 & 6.766 & 5.153 & 10.296 & 2.248 & 9.681 & 9.539 \\
\hline 20:00:00 & 0.874 & 1.237 & 6.601 & 5.212 & 10.296 & 2.094 & 8.585 & 9.231 \\
\hline 22:00:00 & 1.048 & 1.484 & 6.266 & 4.721 & 10.296 & 2.582 & 9.327 & 10.342 \\
\hline
\end{tabular}

HS: statistically meaningful wave height; T3: statistically meaningful wave period; HT: wave height 1/10; TT: wave period 1/10; NZ: zero ascendant crossings; TB: mean wave period; HB: mean wave height; HV: mean quadratic wave height; HR: quadratic means wave height; HSS: spectral meaningful wave height; T01: mean periods $\mathrm{T} 01=\mathrm{mo} / \mathrm{ml}$; T02: mean periods T02 $=(\mathrm{mo} / \mathrm{m} 2)^{1 / 2}$; TP: peak period; HMAX: maximum height; PMAX: maximum height's wave period; TE: energetic period.

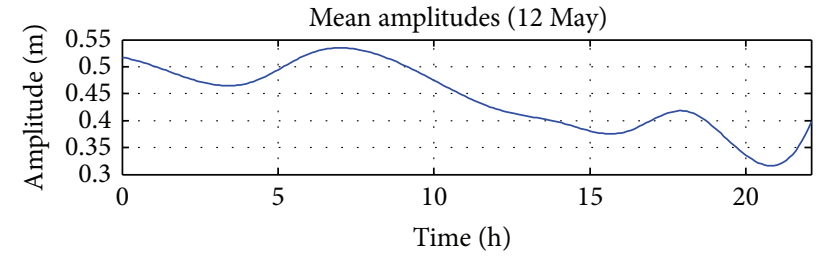

(a)

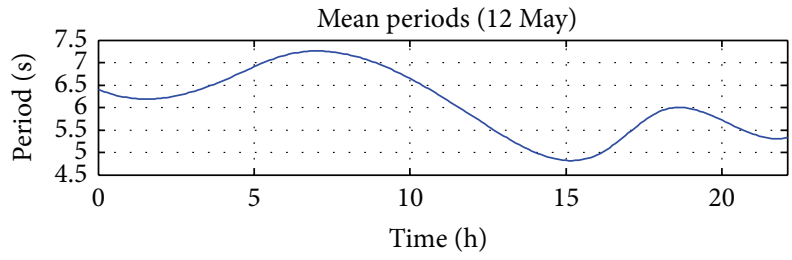

(b)

FIGURE 9: (a) Mean wave amplitude $(H / 2)$ and (b) mean wave periods.

real data and the data predicted by the model, with an error of $3.2 \%$.

4.2.2. Second Case Study: May 12, 2014, $12.00 \mathrm{am}$. For this case study, a 20 -minute dp data series with $2 \mathrm{~Hz}$ sampling rate was selected as shown in Figure 12. According to these data, the real mean pressure drop is $2893.1 \mathrm{~Pa}$ while the theoretical pressure drop computed by the model is $2867.7 \mathrm{~Pa}$, reducing the error to $0.9 \%$.

4.2.3. Third Case Study: May 12, 2014, 16.00 pm. For this case study, a 20 -minute dp data series with $2 \mathrm{~Hz}$ sampling rate was selected as shown in Figure 13. According to these data, the real mean pressure drop is $2797.2 \mathrm{~Pa}$ while the theoretical pressure drop computed by the model is $2827.4 \mathrm{~Pa}$, with an error of $1.1 \%$.

The previous results can be summed up as in Table 3.
As it can be observed, the theoretical results obtained from the proposed mean value model match the real measured experimental data, with a mean error of $1.74 \%$ for the three case studies considered. These results may be extended as shown in Figure 14, where a wider full-day period has been considered. As can be seen, the error remains bounded below $14.67 \%$ with a mean value of $5 \%$, so that similar conclusions may be extracted.

4.3. Instantaneous Values Model. In this section, a detailed instantaneous model based on (16) is implemented as shown in the scheme of Figure 15 and then used for validation purposes using real measured experimental data from Mutriku OWC wave plant.

As shown in Figure 15, the model has two main parts: the capture chamber dynamics that calculates the airflow speed from the input wave features and the turbine dynamics that 


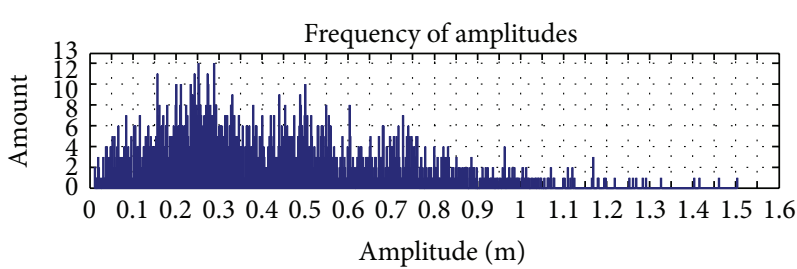

(a)

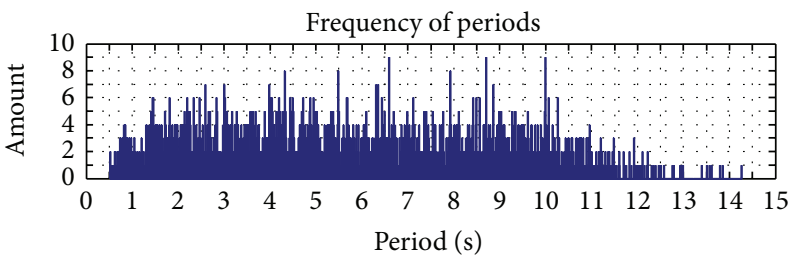

(b)

FIGURE 10: (a) Histogram of wave amplitudes and (b) histogram of wave periods.

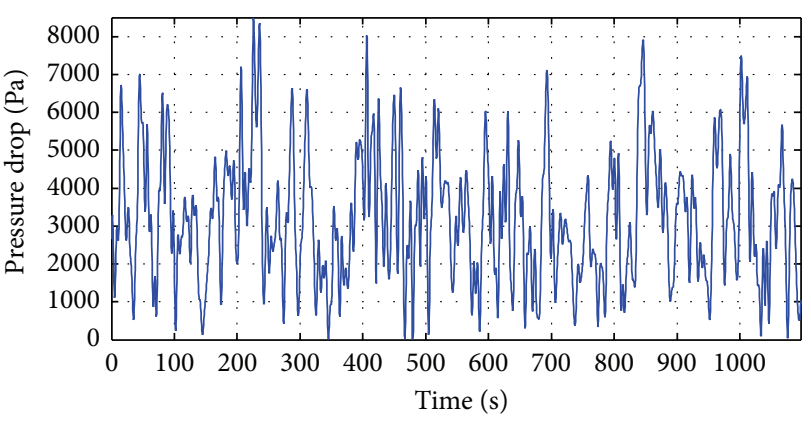

FIGURE 11: Real pressure drop on May 12, $6.00 \mathrm{am}$.

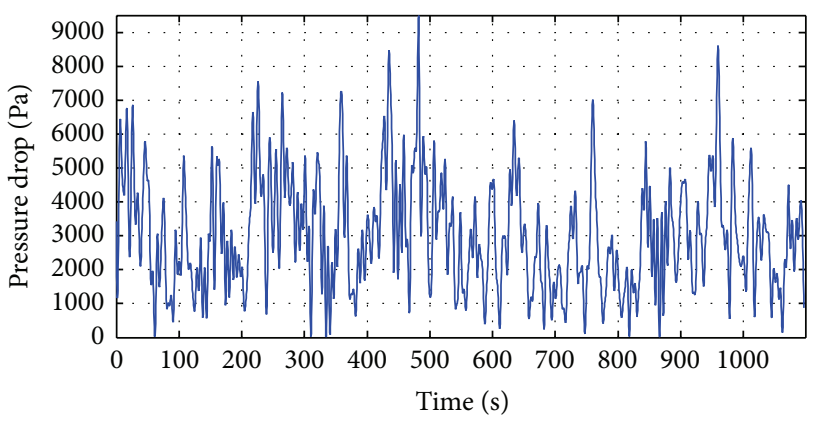

FIGURE 12: Real pressure drop on May 12, $12.00 \mathrm{am}$.

TABLE 3: Wave features and validation results (mean value model).

\begin{tabular}{lcccc}
\hline Date & Hour & $\mathrm{dp}_{\text {real }}(\mathrm{Pa})$ & $\mathrm{dp}_{\text {theoretical }}(\mathrm{Pa})$ & Error \\
\hline $12 / 5 / 14$ & $6: 00$ & 3018 & 2921.3 & $3.2 \%$ \\
$12 / 5 / 14$ & $12: 00$ & 2893.1 & 2867.7 & $0.9 \%$ \\
$12 / 5 / 14$ & $16: 00$ & 2797.2 & 2827.4 & $1.1 \%$ \\
\hline
\end{tabular}

computes the pressure difference due to the airflow passing through the blades and the rotational speed of the turbogenerator module.

In order to validate the model, three different case studies corresponding to those of the previous section are considered: May 12, 2014, 6.00 am; May 12, 2014, 12.00 am; and May 12, 2014, $16.00 \mathrm{pm}$ (see Table 4). For each case, illustrative comparisons of the real experimental and the theoretical model predicted pressure drop are displayed in Figures 16-18.

As it can be seen, the real experimental and theoretically calculated pressure drop outputs coincide, presenting almost the same mean values and the same wave form. However, it

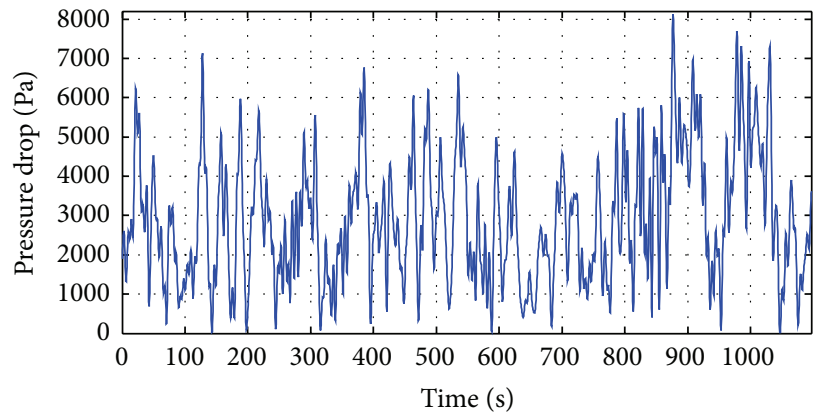

Figure 13: Real pressure drop on May 12, 16.00 pm.

TABLE 4: Wave features for instantaneous values models.

\begin{tabular}{lccc}
\hline Date & Hour & $a(\mathrm{~m})$ & $T(\mathrm{~s})$ \\
\hline $12 / 5 / 14$ & $6: 00$ & 0.5261 & 7.1826 \\
$12 / 5 / 14$ & $12: 00$ & 0.4196 & 5.7668 \\
$12 / 5 / 14$ & $16: 00$ & 0.378 & 4.977 \\
\hline
\end{tabular}

may be observed that the predicted and measured data are not of the same order of magnitude. It has been represented in this way so that the matching can be more easily appreciated. This peak values difference is due to the nature of the model, which considers the instantaneous wave data series as representative monochromatic wave trains at each period at hand, so that a strain-softening effect is achieved. Nevertheless, it must be taken into account that these values refer to pressure drop, and therefore the difference does not affect the power extraction.

\section{Conclusions}

One of the potential solutions for the current global warming problem is the use of ocean energy and, in particular, Oscillating Water Columns (OWCs) technology based energy converters. This kind of device is used to convert the mechanical energy of waves into an airflow that moves a turbine coupled to an induction generator. While the study of the turbogenerator module is already a relatively mature issue, obtaining models for the OWC chamber is still an open research area. In this context, this paper has focused on the development of an analytical model for the OWC capture chamber in this kind of system and its interaction with ocean waves. The proposed model has been successfully tested and validated by means of 


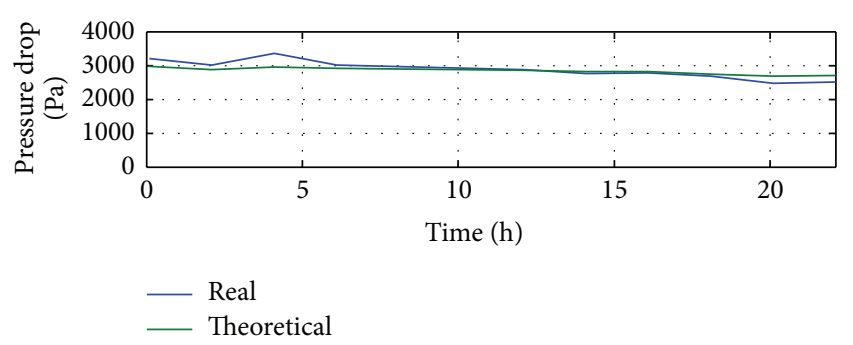

(a)

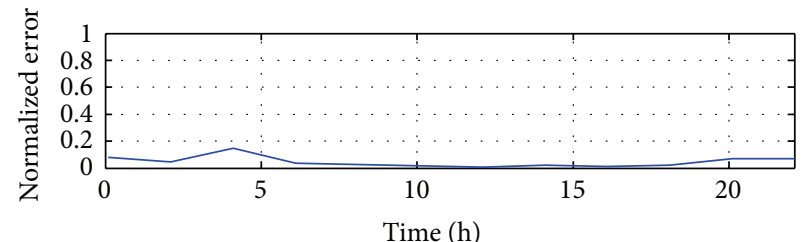

(b)

FIGURE 14: (a) Real versus theoretical pressure drops and (b) normalized error.

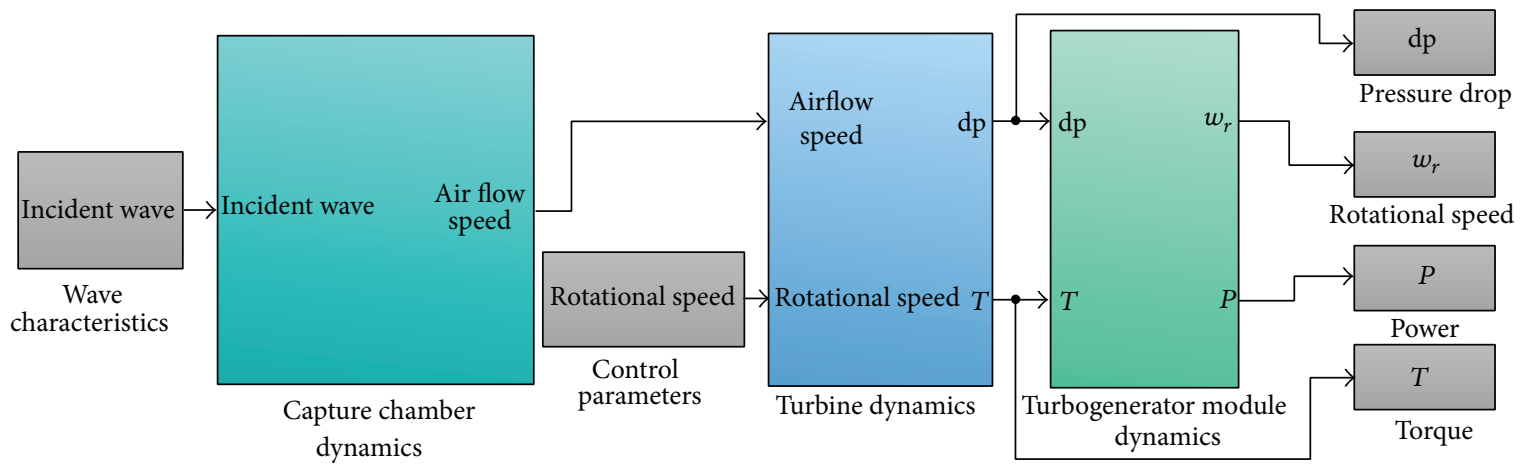

FIGURE 15: Instantaneous values model.

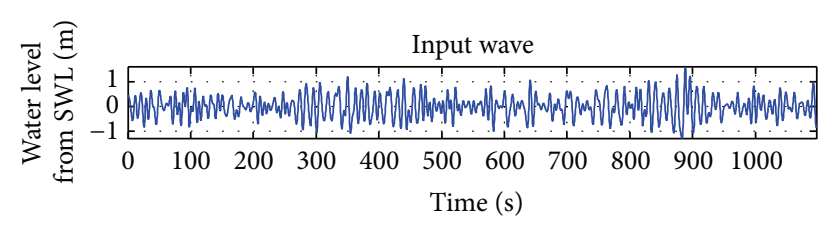

(a)

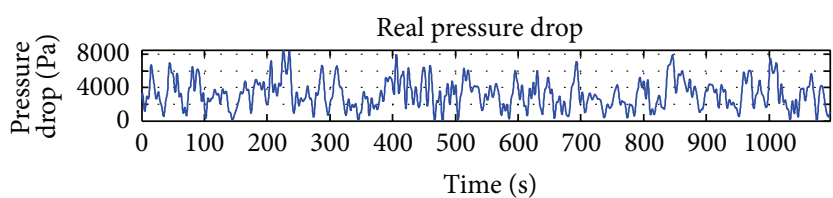

(b)

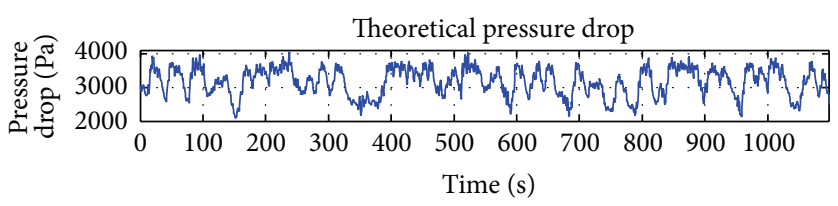

(c)

FiguRE 16: Wave surface (a) and real (b) and theoretical (c) pressure drop on May 12, 6:00 am.

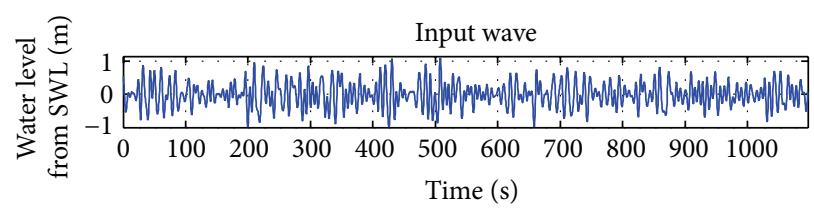

(a)

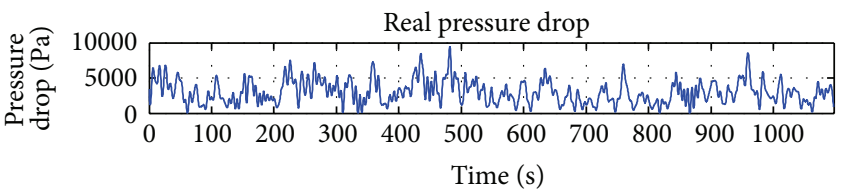

(b)

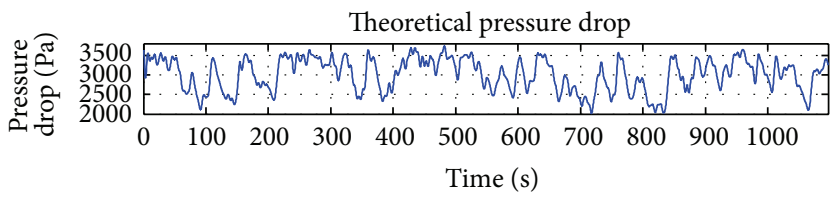

(c)

FIgURE 17: Wave surface (a) and real (b) and theoretical (c) pressure drop on May 12, 12:00 am. 


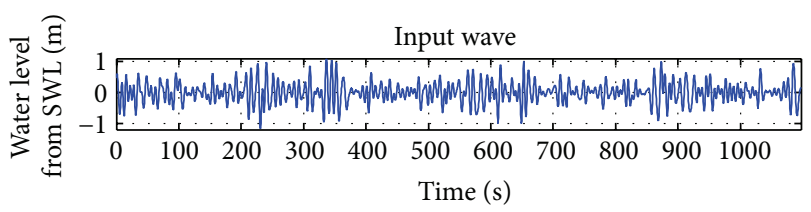

(a)

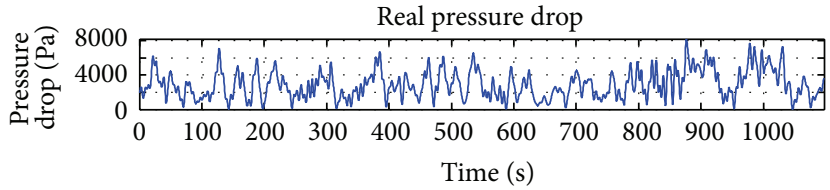

(b)

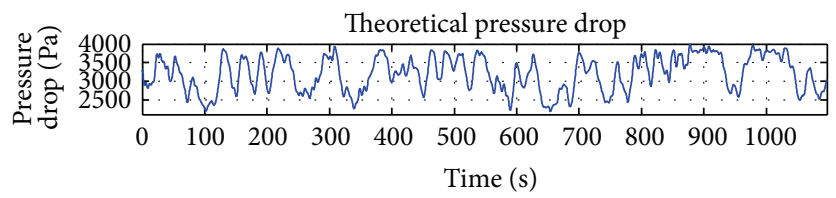

(c)

FigURE 18: Wave surface (a) and real (b) and theoretical (c) pressure drop on May 12, 16:00 pm.

experimental results for the particular case of Mutriku OWC wave power plant, affording excellent results.

\section{Conflict of Interests}

The authors declare that there is no conflict of interests regarding the publication of this paper.

\section{Acknowledgments}

This work was supported in part by the University of the Basque Country (UPV/EHU) through Research Project GIU14/07 and Research and Training Unit UFI11/07 and by the Eurorégion Aquitaine Euskadi through Research Project WAKE, Wave energy AKitania-Euskadin. The authors are also grateful for the collaboration of the Basque Energy Board (EVE) through Agreement UPV/EHUEVE23/6/2011, the Spanish National Fusion Laboratory (EURATOMCIEMAT) through Agreement UPV/EHUCIEMAT08/190, and EUSKAMPUS-Campus of International Excellence. They would also like to thank Stephane Abadie and Matthias Delpey from EA 4581 SIAME UPPA and Rivages ProTech, respectively, for their help within WAKE, and Yago TorreEnciso and Olatz Ajuria from EVE for their collaboration and help.

\section{References}

[1] M. G. Sevillano, I. Garrido, A. J. Garrido et al., "Observerbased real-time control for the poloidal beta of the plasma using diamagnetic measurements in tokamak fusion reactors," in Proceedings of the 50th IEEE Conference on Decision and Control and European Control Conference (CDC-ECC '11), pp. 7536-7542, IEEE, Orlando, Fla, USA, December 2011.

[2] A. J. Garrido, I. Garrido, M. G. Sevillano et al., "Linear models for plasma current control in tokamak reactors," in Proceedings of the 11th International Conference on Control Automation Robotics \& Vision (ICARCV '10), pp. 78-84, IEEE, Singapore, December 2010.

[3] A. J. Garrido, I. Garrido, O. Barambones, P. Alkorta, and F. J. Maseda, "Simple linear models for plasma control in tokamak reactors," in Proceedings of the International Conference on
Control, Automation and Systems (ICCAS '08), pp. 2429-2432, IEEE, Seoul, Republic of Korea, October 2008.

[4] J. V. Ringwood, G. Bacelli, and F. Fusco, "Energy-maximizing control of wave-energy converters: the development of control system technology to optimize their operation," IEEE Control Systems, vol. 34, no. 5, pp. 30-55, 2014.

[5] A. J. Garrido, I. Garrido, M. Amundarain, M. Alberdi, and M. De la Sen, "Sliding-mode control of wave power generation plants," IEEE Transactions on Industry Applications, vol. 48, no. 6, pp. 2372-2381, 2012.

[6] A. González and A. Sala, "Weighted-delay predictor-based control: performance and robustness analysis with time-varying delay," Revista Iberoamericana de Automática e Informática Industrial RIAI, vol. 11, no. 2, pp. 155-166, 2014.

[7] M. Delucchi, "Wind, water and solar power for the world," IEEE Spectrum, 2011.

[8] M. Z. Jacobson and M. A. Delucchi, "Providing all global energy with wind, water, and solar power, part I: technologies, energy resources, quantities and areas of infrastructure, and materials," Energy Policy, vol. 39, no. 3, pp. 1154-1169, 2011.

[9] M. Z. Jacobson and M. A. Delucchi, "Providing all global energy with wind, water, and solar power, part II: reliability, system and transmission costs, and policies," Energy Policy, vol. 39, no. 3, pp. 1170-1190, 2011.

[10] European Commission, Ocean Energy, 2015, http://ec.europa .eu/research/energy/eu/index_en.cfm?pg=research-ocean.

[11] European Ocean Energy Association, 2013 Industry Vision Paper, 2013, http://www.oceanenergy-europe.eu/images/Publications/European_Ocean_Energy-Industry_Vision_Paper_2013 .pdf.

[12] D. Y. Goswami and F. Kreith, Energy Conversion, CRC Press, New York, NY, USA, 2007.

[13] H. Polinder and M. Scuotto, "Wave energy converters and their impact on power systems," in Proceedings of the International Conference on Future Power Systems, Amsterdam, The Netherlands, November 2005.

[14] M. A. Ormaza, M. A. Goitia, A. J. G. Hernández, and I. G. Hernández, "Neural control of the Wells turbine-generator module," in Proceedings of the IEEE Conference on Decision and Control, pp. 7315-7320, IEEE, Shanghai, China, December 2009.

[15] A. J. Garrido, M. De La Sen, J. C. Soto, O. Barambones, and I. Garrido, "Suboptimal regulation of a class of bilinear interconnected systems with finite-time sliding planning horizons," 
Mathematical Problems in Engineering, vol. 2008, Article ID 817063, 26 pages, 2008.

[16] A. J. Garrido, I. Garrido, M. Alberdi, M. Amundarain, O. Barambones, and J. A. Romero, "Robust control of oscillating water column (OWC) devices: power generation improvement," in Proceedings of the OCEANS-San Diego, pp. 1-4, MTS/IEEE, San Diego, Calif, USA, September 2013, article 6740982.

[17] Y. Torre-Enciso, Mutriku Wave Power Plant: From Conception to Reality, European Federation of Agencies and Regions for Energy and the Environment (FEDARENE), Brussels, Belgium, 2009.

[18] Y. Torre-Enciso, I. Ortubia, L. I. López de Aguileta, and J. Marqués, "Mutriku wave power plant: from the thinking out the reality," in Proceedings of the 8th European Wave and Tidal Energy Conference, pp. 319-329, 2009.

[19] A. El Marjani, F. Castro Ruiz, M. A. Rodriguez, and M. T. Parra Santos, "Numerical modelling in wave energy conversion systems," Energy, vol. 33, no. 8, pp. 1246-1253, 2008.

[20] A. Thakker and R. Abdulhadi, "Effect of blade profile on the performance of wells turbine under unidirectional sinusoidal and real sea flow conditions," International Journal of Rotating Machinery, vol. 2007, Article ID 51598, 9 pages, 2007.

[21] L. M. C. Gato, V. Warfield, and A. Thakker, "Performance of a high-solidity wells turbine for an OWC wave power plant," Journal of Energy Resources Technology, vol. 118, no. 4, pp. 263268, 1996.

[22] M. Inoue, K. Kaneko, T. Setoguchi, and T. Saruwatari, "Studies on the Wells turbine for wave power generator (turbine characteristics and design parameter for irregular wave)," JSME International Journal, vol. 31, no. 4, pp. 676-682, 1988.

[23] T. Setoguchi and M. Takao, "Current status of self rectifying air turbines for wave energy conversion," Energy Conversion and Management, vol. 47, no. 15-16, pp. 2382-2396, 2006.

[24] S. Raghunathan, "Performance of the Wells self-rectifying turbine," Aeronautical Journal, vol. 89, no. 1369, pp. 369-379, 1985.

[25] V. Jayashankar, S. Anand, T. Geetha et al., "A twin unidirectional impulse turbine topology for OWC based wave energy plants," Renewable Energy, vol. 34, no. 3, pp. 692-698, 2009.

[26] J. Klamka, A. Czornik, M. Niezabitowski, and A. Babiarz, "Controllability and minimum energy control of linear fractional discrete-time infinite-dimensional systems," in Proceedings of the 11th IEEE International Conference on Control \& Automation (ICCA '14), pp. 1210-1214, Taichung, Taiwan, June 2014.

[27] M. De la Sen, "Adaptive sampling for improving the adaptation transients in hybrid adaptive control," International Journal of Control, vol. 41, no. 5, pp. 1189-1205, 1985.

[28] A. Babiarz, A. Czornik, J. Klamka, and M. Niezabitowski, "Controllability of discrete-time linear switched systems with constrains on switching signal," in Proceedings of the 7th Asian Conference on Intelligent Information and Database Systems, Part I (ACIIDS '15), Bali, Indonesia, vol. 9011 of Lecture Notes in Artificial Intelligence, pp. 304-312, 2015.

[29] M. De La Sen, "Stability of composite systems with an asymptotically hyperstable subsystem," International Journal of Control, vol. 44, no. 6, pp. 1769-1775, 1986.

[30] A. Babiarz, J. Klamka, R. Zawiski, and M. Niezabitowski, "An approach to observability analysis and estimation of human arm model," in Proceedings of the 11th IEEE International Conference on Control \& Automation (ICCA '14), pp. 947-952, IEEE, Taichung, Taiwan, June 2014.
[31] M. De la Sen, "About robust stability of caputo linear fractional dynamic systems with time delays through fixed point theory," Fixed Point Theory and Applications, vol. 2011, Article ID 867932, 2011.

[32] A. Czornik and M. Niezabitowski, "Alternative formulae for lower general exponent of discrete linear time-varying systems," Journal of the Franklin Institute, vol. 352, no. 1, pp. 399-419, 2015.

[33] M. De la Sen, "On the robust adaptive stabilization of a class of nominally first-order hybrid systems," IEEE Transactions on Automatic Control, vol. 44, no. 3, pp. 597-602, 1999.

[34] J. Klamka, A. Czornik, M. Niezabitowski, and A. Babiarz, "Trajectory controllability of semilinear systems with delay," in Intelligent Information and Database Systems, vol. 9011 of Lecture Notes in Computer Science, pp. 313-323, Springer, 2015.

[35] A. J. Garrido, I. Garrido, O. Chalatsakos et al., "Modelling and control of the UPV/EHU stellarator," in Proceedings of the 23th Mediterranean Conference on Control and Automation (MED '15), pp. 421-427, IEEE, Torremolinos, Spain, June 2015.

[36] O. Barambones and A. J. Garrido, "An adaptive variable structure control law for sensorless induction motors," European Journal of Control, vol. 13, no. 4, pp. 382-392, 2007.

[37] M. De la Sen, "Multirate hybrid adaptive control," IEEE Transactions on Automatic Control, vol. 31, no. 6, pp. 582-586, 1986.

[38] M. G. Sevillano, I. Garrido, and A. J. Garrido, "Sliding-mode loop voltage control using ASTRA-Matlab integration in Tokamak reactors," International Journal of Innovative Computing, Information and Control, vol. 8, no. 9, pp. 6473-6489, 2012.

[39] I. Garrido, B. Lee, G. E. Fladmark, and M. S. Espedal, "Convergent iterative schemes for time parallelization," Mathematics of Computation, vol. 75, no. 255, pp. 1403-1428, 2006.

[40] M. Alberdi, M. Amundarain, A. J. Garrido, I. Garrido, O. Casquero, and M. De La Sen, "Complementary control of oscillating water column-based wave energy conversion plants to improve the instantaneous power output," IEEE Transactions on Energy Conversion, vol. 26, no. 4, pp. 1021-1032, 2011.

[41] I. Garrido, J. A. Romero, A. J. Garrido, D. Lucchin, E. Carrascal, and G. Sevillano-Berasategui, "Internal inductance predictive control for Tokamaks," in Proceedings of the World Automation Congress (WAC '14), pp. 628-633, August 2014.

[42] R. Nistal, M. De La Sen, S. Alonso-Quesada, A. Ibeas, and A. J. Garrido, "On the stability and equilibrium points of multistaged SI $(n) R$ epidemic models," Discrete Dynamics in Nature and Society, vol. 2015, Article ID 379576, 15 pages, 2015.

[43] M. G. Sevillano, I. Garrido, and A. J. Garrido, "Control-oriented Automatic System for Transport Analysis (ASTRA)-matlab integration for tokamaks," Energy, vol. 36, no. 5, pp. 2812-2819, 2011.

[44] O. Barambones, A. J. Garrido, F. J. Maseda, and P. Alkorta, "An adaptive sliding mode control law for induction motors using field oriented control theory," in Proceedings of the IEEE International Conference on Control Applications (CCA '06), pp. 1008-1013, IEEE, Munich, Germany, October 2006.

[45] P. Alkorta, O. Barambones, A. J. Garrido, and I. Garrido, "SVPWM variable structure control of induction motor drives," in Proceedings of the IEEE International Symposium on Industrial Electronics (ISIE '07), pp. 1195-1200, June 2007.

[46] A. F. D. O. Falcao, L. C. Vieira, P. A. P. Justino, and J. M. C. S. André, "By-pass air-valve control of an OWC wave power plant," Journal of Offshore Mechanics and Arctic Engineering, vol. 125, no. 3, pp. 205-210, 2003.

[47] P. D. Komar, Beach Processes and Sedimentation, Prentice Hall, Upper Saddle River, NJ, USA, 1998. 
[48] A. Chadwick, J. Morfett, and M. Borthwick, Hydraulics in Civil and Environmental Engineering, Spon Press, London, UK, 2004.

[49] W. K. Tease, J. Lees, and A. Hall, "Advances in oscillating water column air turbine development," in Proceedings of the 7th European Wave and Tidal Energy Conference, Porto, Portugal, 2007.

[50] J. C. Garcia, C. Diego, P. F. de Arróyabe, C. Garmendia, and D. Rasilla, Weather between the Sea and the Mountain, University of Cantabria, Santander, Spain, 2004.

[51] M. Sameti and E. Farahi, "Output power for an oscillating water column wave energy convertion device," Ocean and Environmental Fluid Research, vol. 1, no. 2, pp. 27-34, 2014.

[52] J. P. Le Roux, "An extension of the Airy theory for linear waves into shallow water," Coastal Engineering, vol. 55, no. 4, pp. 295301, 2008.

[53] F. D. Bianchi, H. de Battista, and R. J. Mantz, Wind Turbine Control Systems: Principles, Modelling and Gain Scheduling Design, chapter 2, Springer, Berlin, Germany, 2002. 


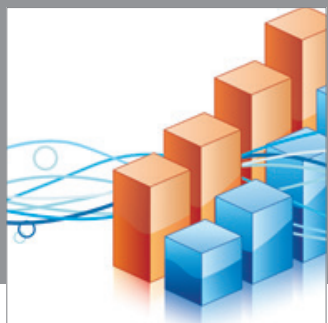

Advances in

Operations Research

mansans

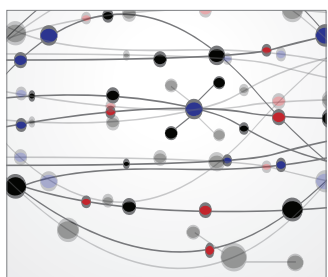

The Scientific World Journal
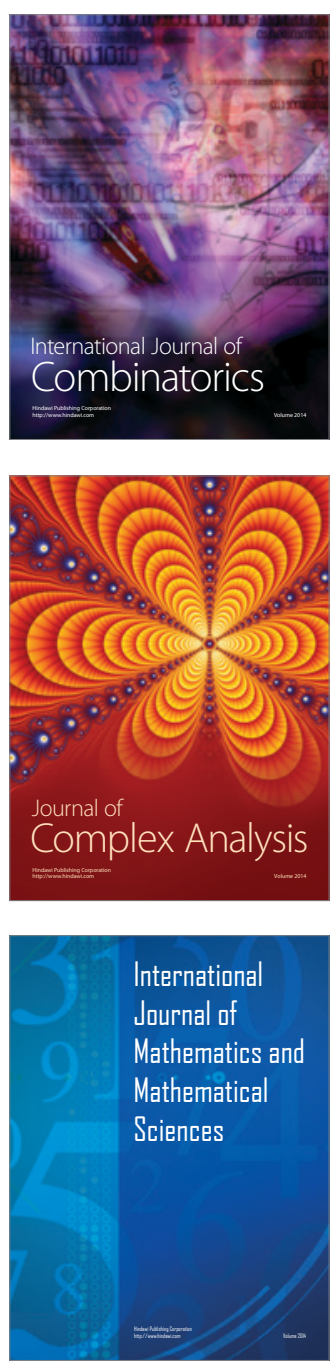
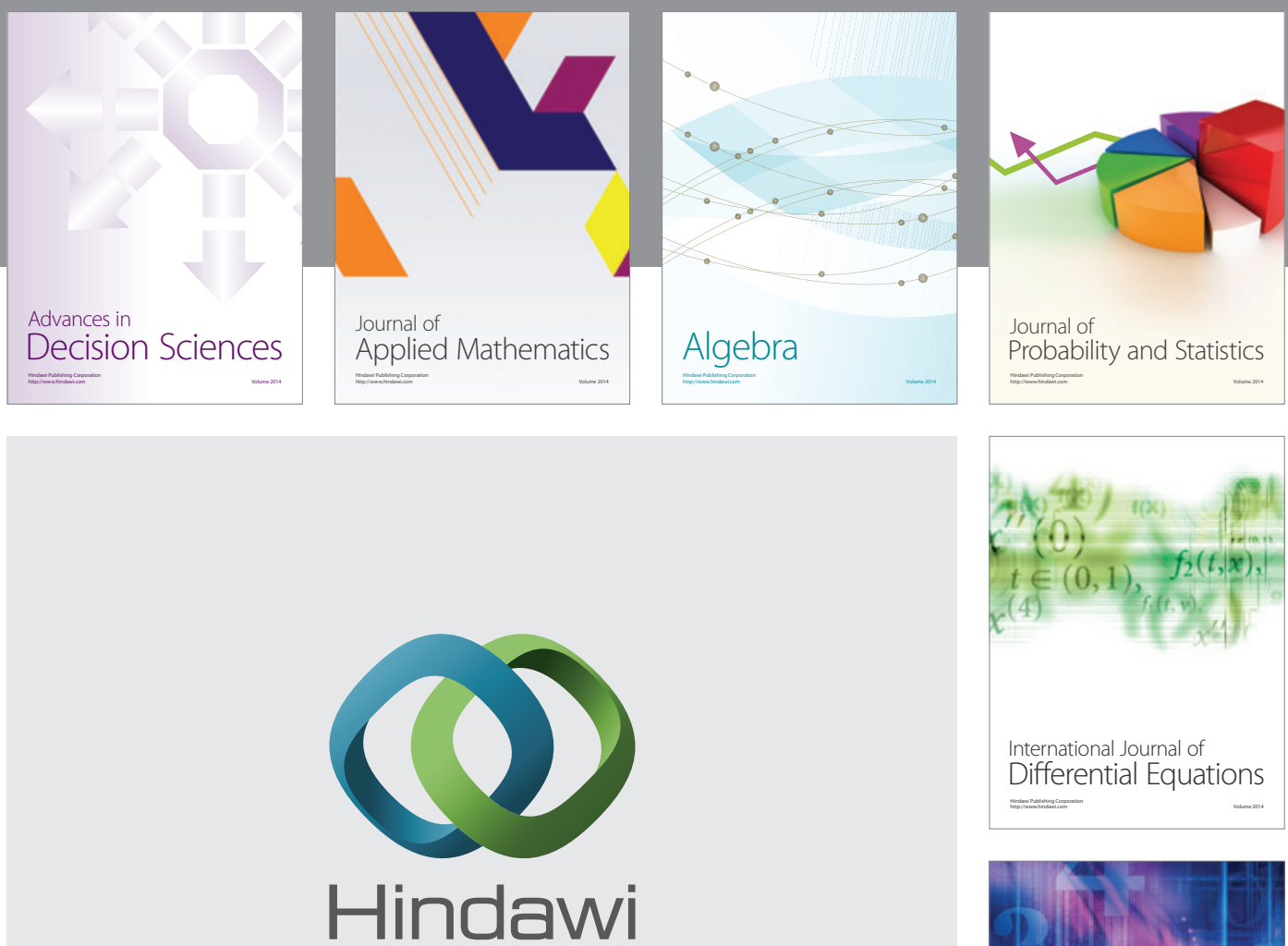

Submit your manuscripts at http://www.hindawi.com
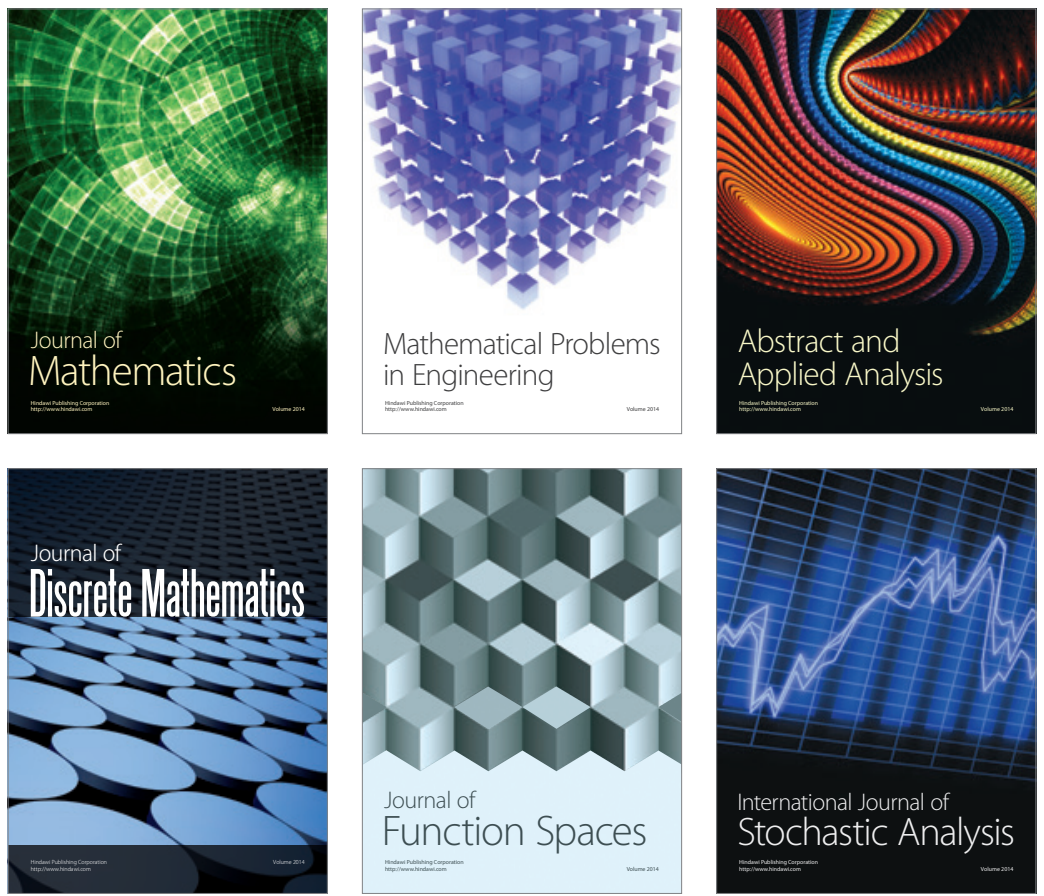

Journal of

Function Spaces

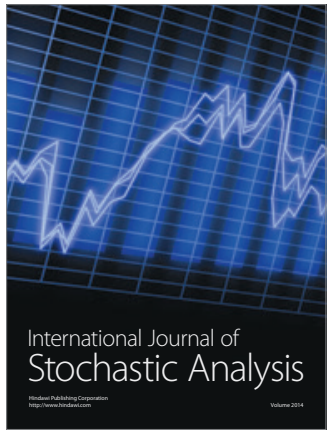

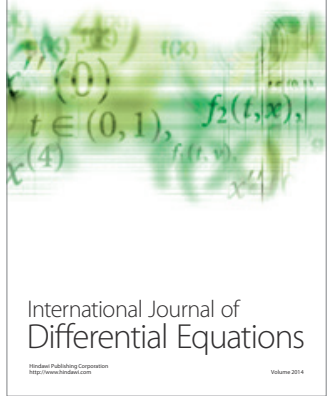
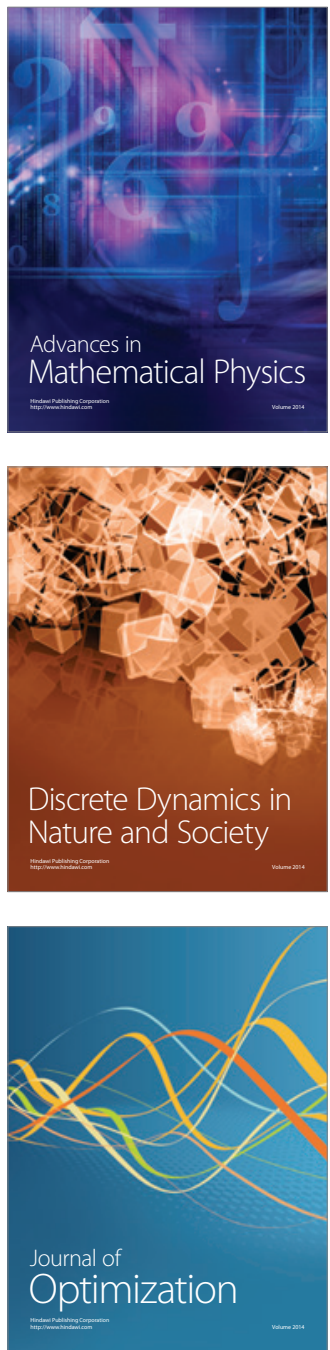